\title{
HUKUM LINGKUNGAN HIDUP SERTA PEMBUANGAN SAMPAH SEMBARANGAN
}

\author{
Endang Astuti \\ Email: 2010128220009@ulm.ac.id \\ Program Studi Pendidikan IPS Fakultas Keguruan dan Ilmu Pendidikan \\ Universitas Lambung Mangkurat \\ Banjarmasin
}

\begin{abstract}
ABSTRAK
Lingkungan hidup merupakan sebuah daya serta kondisi dan semua benda yang dapat masuk kedalam tingkah atau pun perbuatan yang termasuk dalam sebuah ruang manusia yang berada pada pengaruh dari adanya kelangsungan hidup dan kesejahteraan menusia. Maslah lingkungan dapat sangat merusak kehidupan salah satunnya ialah membuang sampah sembarangan yang mana pembuangan sampah yang sembarangan ialah ulah dari manusia, oleh karena itu adanya suatu hukum yanng menjelaskan tentang pencemaran lingkungan serta adanya tindak pidana supaya manusia tidak membuang sampah sembarangaan. Oleh karena itu dalam artikel ini bertujuan agar manusia tidak membuang sampah sembarangan dan dapt mentaati perturan atau hukum yyang telah di tetapkan oleh pemerintah ataupun kepala deerah setempat. Dengan metode kualitatif deskriptif maaka artikel ini dapatt menghasilkan suatu dataa yang telah dianalisis dan menempatkan pembahsan pada tempatnya dan sehingga dalam penulisan ini maka manuasia sadar akan lingkungan hidup didalam kehidupananya serta sadar akan adanya hukum dan peaturan yang harus di taati.
\end{abstract}

Kata kunci : Sampah, hukum, lingkungan

\section{PENDAHULUAN}

Lingkungan berbagai macam lingkungan yang ada di dalam kehidupan kita, seperti lingkungan fisik atau juga disebut anorgganik yang dimana terdiri dari sebuah gaya yaitu kosmik dan juga fisiogeografis yang mana lingkungan fisik ini seperti udara, tanah, radiasi, gaya tarik, ombak dan sebagainya. Kedua ialah lingkungan biologi atau ( organik) jadi lingkungan ini seperti parasit, 
hewan, tumbuhan, dan juga proses-proses biologi seperti reproduksi, petumbuhan dan juga sebagainya. Yang ketiga ialah lingkungan sosial, lingkungan sosial merupakan lingkungan atau sebuah tempat kita beraktivitas dan tempat kita bersosialisasi serta interaksi. Permasalahan lingkungan sangatlah banyak sehingga permasalahan lingkungan hidup ini sangat bahaya bagi kehidupaan makluk hidup, permasalahaan lingkungan hidup ini dapat berupa banjir, tanah longsor dan penumpukan sampah yang sangat banyak. (Deasy, A. (2020).)

Sampah yang sangat banyak ini sangat berbahaya bagi lingkungan disekitarnya dan sampah juga sampah di indonesia sangat lah lebih banyak dari pada negra lain. ( Ahya, RR, Syaharuddin, S., \& Rahman, AM (2020) indonesia memiliki catatan buruk akibt adanya sampah yang begitu banyak di daerah perairan ( sungai), sampah-sampah yang sering muncul di perairan ialah sampah plastik yang tidak ramah lingkungan. Sampah-sampah ini sangat banyak berada di sungai dan tempattempat perairan lainnya, dan indonesia ini di berikan gelar sebagai negara dengan sebuah julukan sebagai negara kedua penghasil sampah plastik di dunia.( Ahya, RR, Syaharuddin, S., \& Rahman, AM (2020). Artikel ini akan mengangkat tentang hukum di dalam lingkungan hidup dan serta pembuangan sampah sembarangan yang akan merusak lingkungan hingga juga menumbuhkan kesadaran manusia tentang adanya pelanggaran hukum mengenai pencemaran lingkungan .

\section{METODE}

Dalam pembahasan di artikel ini saya menggunakan sebuah metode kualitatif, yang mana dalam metode ini saya mengumpulkan beberapa data tentang permaslahan lingkungan hidup yang berpacu pada permasalahan dari adanya banyak sampah di indonesia, dan pengumpulan data tersebut menggunakan beberapa sumber yang dapat di percaya, dengan menggunakan tahap pada sistem dideskripsikan sehingga pada akhirnya dapat di tafsirkan sesuai dengan analisis dari penulis. Sumber- sumber ini di dapat dari berbagai jenis jurnal yang dapat di pilah dan dengan sebaik mungkin agar penggumpulan data dapat di tulis dan di tempatkan di dalam tempatnya. Dalam metode ini dapat dengan menggunnakan dan mengandalkan serta mengumpulkan data dari jurnaljurnal yang bersumber yang ada di Google Cendekia yang mana ada 10 jurnal yang akan menggunkan analiss terlebih dahulu dan dapat di himpunnya pembahasan yang akan sesuai dengan yang akan di bahas. 


\section{PEMBAHASAN}

Permasalahan lingkungan sangat dapat merusak kehidupan di sekitar manusia, hewan, tumbuhan dan sebagainya. Karena permasalahan lingkungan sangat banyak macamnya seperti, banjir, tanah longsor, dan sampah. Sampah pada setiap harinya bertambah banyak entah di darat, disungai dan di laut. Sampah ini membuat terjadinya sebuah hal yang tidak di inginkan dan juga sampah ini ada karena ulah manusia, yang biasanya membuang di sungai, atau juga membuang ketempat yang sebarangan. Dan pada sekarang sebab dari perbuatan manusia, sampah di lingkungan di daerah indonesia semakin menumpuk hingga menjadi sebuah gunung yang dapat didaki. Sampah di indonesia memiliki peringkat kedua dari berbagai negara, karena sampah pelastik di indonesia lebih banyak dari pada negara lain. (Hadiyati, N., \& Cindo, C. (2021))

Permukiman yang berada di dekat pembuangaan sampah akhir sangat kotor, selain kotor air di sungai pun sudah tercemar oleh limbah pabrik, dan lingkungan itu tidak layak bagi seseorang yang tinggal disana, sebab di lingkungan tersebut sangatlah tidak nyaman dan juga dapat mudah tertularnya penyakit, karena daerah yang tinggal di lingkungan tersebut sangat lah kumuh, dan juga kekurangan air bersih karena sungai untuk mandi dan cuci pakaian telah kotor oleh sisa limbah pabrik tersebut, sehingga untuk minum dan mandi mereka harus mencari air bersih untuk minum. (Ahya, RR, Syaharuddin, S., \& Rahman, AM (2020).

Bahkan ada undang- undang yang telah berhubungan dengan ingkungan dii indonesia tentang pengelolaan wilayah yang berada di sungai dan juga hunian sebenarnya sudah banyak, dan bagaimana para pemerintah memiliki ketegasaaan akan melaksanaakan dan juga mengatur tentang menegakkan aturan yang sudah ada sebelumnya, yang mana termasuk didalamnya sebuah kewajiban pemerintah untuk melakukan monitoring tentang pembuangan limbah industri yang berdasarkan PP No,82/2001 tentangg pengolaan kualitas air dan pengendalian pencemaran. Dan jugga pemerintah harus juga bergerak dalam adanya pembuangan limbah industri yang sembarangan. (Syaharuddin, S., Hidayanti, H., \& Mutiani, M. (2020).

Kehidupan seseorang disekitar sampah merupakan kehidupan yang tidak mau dimiliki oleh orang lain, tapi lain hal nya dengan orang-orang yang tinggal di sana, mereka tidak mempunyai pilihan untuk tidak tinggal disana, di daerah permukiman dekat sampah sangatlah menggagu oleh 
aroma yang tidak sedap, dan aroma tersebut bagi yang sudah biasa didaerah tersebut tidak merasa resah, karena orang yang di permukiman di dekat tempat pembuangan sampah itu prioritas perkerjaan mereka mengumpulkaan botol plastik bekas dan menjual barang tersebut di pembelian botol bekas.

Hukum lingkungan ialah sautu bidang ilmu yang masih awal atau masi muda, yang mana perkembangan yang baru terjadi. Dan apabila dikaitkan dengan seuah peraturan tentang perundangundangan yang mengatur berbagai macam aspek linggungan, maka pnjaang atu pendeknya dri suatu sejarah dari peraturan tersebut tergantung dari apa adanya yangg dipandang sebagai environmental concern. (Deasy, A. (2020).

Hukum dari lingkungan modern menetapkan tentang ketentuan dan juga norma-norma yang berguna sebgai pengatur dri danya tindak perbutn manusia dengn memiliki sebuah tujuan melindungi lingkuangan dari adanya kerusakan dan suatu kemerosotan mutunya agar dapat menjamin kelestarian dan secara terus menerus dapat digunakan oleh generasi sekarang dan seterusnya atau mendatang, dan sebalikny.( Syaharuddin, S., Hidayanti, H., \& Mutiani, M. (2020

hukum lingkungan klasik merupakan hukuman yang menetapkan sebuh ketentuan dan norma norma yang bertujuan untuk menjamin penggunaan, dan juga hukum modern merupakan sebuah berorientasi kepda suatu lingkungan, yang sehingga sifat dan watak dari sebuah liingkungan itu sendiri dapat lebih banyak berguru kepada sebuah ekologi, dengan sebuah orientasi, kepada lingkungan ini, dan maka lingkungan modern ini memiliki sifat yang utuh menyeluruh atau disebut komperehesif, intergral, yang mana selalu berada dalam suatu dinamik dengan memiliki sebuah sifat dan wataknya yang luwes. Adapun hukum lingkungan intenasional yang mana ialah sebuah 
perjanjian bilateral antar negara, dan perjanjian regional yang mana karena semuanya adalah sumber hukum yang supranasional. (Ahya, RR, Syaharuddin, S., \& Rahman, AM (2020).

Pencemaran lingkungan serta kerusakan tidak hnya menjadi masalah nasional akan tetpi menjadikaan masalh antar negara, regional, dan juga globbal. Dunia akan semkin sempit, hubungan negara yang semakin dekat dengan berbagai negara lain dan makin tergantung satu dengan yang lain, sehingga akan menimbulkan pencemaran pun akan menjadikan semakin luas, sehingga kadang dapaat melewati batas- batas negara ddalam bentuk pencemaraan air sungai, emisi udara, kebakaran hutan, dan jugga sebbuah pencemaran minyak yang ada di laut dan seterusnya. Pembuangan limbah berbaahaya sangat lah banyak di berbagai negara, sebagai contoh seperti limbah yang sangaat berbahaya seperti di hulu sungai Rjin yang berdampak pada negara jerman dan juga belanda bahkan juga berbagai negara yang berpantai di laut utara. Sera kebakaran hutan yang berada di serawak yang mana keakaran tersebut akan mudah merembet ke daerah kalimantan barat dan juga seblaiknya semua ini memerlukan sebuah pengaturan yang khuusus yang bersifat supranasional. Bahkan kenyataan bocornya ozon terseut dapat membangunkan setiap negara untuk dapat tuut seta menamgu langinya dengan konferensi dan juga konvensi internasional.( Suharwati, S. I., \& Rahman, A. M. (2018).

Dalam sebuah ruang nasional, hukum lingkungan menempati titik silang pelbaga bagian dari adanya hukum klasik, yaitu hukum publik, hukum publik dalah sebuah hukum pidana, hukum pemerintahan ( administratif), hukum pajak, hukum tata negara, bahkan hukum agraria pun berkaitan dengan hukum lingkungan. Kaitanya dengan UUD 1945 dan hukum tata negara juaga dapat di tujukan pasal 33 ayat (3) UUD 1945 yang menyatakan bahwa " bumi dan air dan juga kekayaan 
alam yang terrkandung di dalamnya dikuuasai oleh negara dan dipergunakan sebesar-besarnya untuk kemakmuran rakyatt”.

Tindak pidana lingkungan hidup dalam unddang undng nomor 32 tahun 2009yang terdiri dari 17 BAB dan juga 127 pasal yanag dapat mengattur secara lebih menyeluruh tentang adanya perlindungan dan juga pengelolaan linngkungan hidup.perbedaaan mendasar antara undang undang nomor 23 tahun 1997 tentang adanya pengelolaan lingkungan hidup atau disebut dengan UUD PLH dengan adanya undang undang ini maka adanya suatu penguatan yang terdapaat dalam uundangundang tentang suatu prinsip-prinsip perlindungan dalam setiap prosees perumusan dan juga adaanya penerapaan instrumen dalam pncegahan dari adanya pencemaran dan juga dari adanya kerusakan lingkungan hidup, yang mendasarkan pada suatu tata kelola pemerintahan yang baik karrena dalam setiap proses pemuurusan dan juga penerapan instrumen pencegahan dari pencemaraan dan juga kerusakan lingkungan hidup juga serta dapat penanggulangan dan penegakan hukum yng mewajibkan pengintegrasian aspek tranparansi, partipasi, akuntabilitas, dan juga keadilaan. (Bachtiar, E., Duwila, A. A., Chaerul, M., Affandy, N. A., Makbul, R., Tanjung, R., ... \& Simarmata, M. M. (2021).

Pemerintahan memeberikan kewenangannya yang sangat luas kepda pemerintah daerah dalam melakukan suatu perlindungan dan juga pengelolaan lingkungan hidup di daerahnya masingmasing yang mana tidak diatur dalam undng-undng nomor 23 tahun 1997 yang mana tentang pengeloan lingkungan hidup. Kesadaran hukum ialah sebuah kesadaaran yang berasal dari dalam diri agar dapatt mematuhi semua peraturn- peraturan yang telah dibuat bersama. Kesadaran hukum jaga ialah kesadaran tentang apa yang seyogyanya kitta lakukan atau kita juga perbuat, terutama perbuatan terhadap orang lain. (Bachtiar, E., Duwila, A. A., Chaerul, M., Affandy, N. A., Makbul, R., Tanjung, R., ... \& Simarmata, M. M. (2021).

Tujuan adaanya kesadaran manusia ini ialah agar manusia sadar aakan adanya hukum sebab, setiap individu pasti memunyai kepentingan yang sangat berbeda-beda. Karena manusia dari awal dia lahir sampai ia wafat pastimemiliki banyak nya kepentingan dan juga mempuyai tujuannya masing-masing, namun juga terkadang dalam suatu prosesnya dalam menjalankan suaatu kepentingan manusia itu diancam oleh bahaya-bahaya sekitarnya atau pun sesama manusia dengan 
yang lainnya, karena manusia dapat melakukan banyak perbuatan yang negaatif seperti pembunuhan, perampasan hak orang lain, bencaanaa alaam dan lain sebagainya. (Suharwati, S. I., \& Rahman, A. M. (2018))

Dampak adanya sampah yang membuang sebarangan ini akan menjadikan suattu pemandagan menjadi rusak dan juga akan medatangkan bau yang sangat bau ( bau tidak sedap), dan jua akan mendatagkan adanya suatu banjir yang memiliki level rendah hingga yang tinggi, dan juga sampah ini mendatangkan berbagai penyakit, karena adanya sampai ini dapat mencemari lingkungan sehingga lingkungan itu tidak terasa nyaman untuk di nikmati lagi. Agarr kita mengurangi adanya sampah ini, maka dari itu kita dapat menangulangi sampah dengan menggunakan cara yang paling sederhana yaitu dengan menumbuhkan kesadaraan yang berada di dalam diri kita sendiri agar dapat tidak membuang sampah dengan sembbarangan, dan juga pemerintah jugga memiliki peran dalam hal tentang ini, dan dengan dalam pperaturan-peraturan dan juga sanksi-sanksi yang dimiliki atau yang ada agar dapat mengharapkan bisa meminimalkan sutu kerusakan lingkungan yang di buat oleh pihak-pihak yang tidak bertanggung jawab. (Suharwati, S. I., \& Rahman, A. M. (2018).

Dampak negatif dari sammpah tersebut juga berdampak akan adannya kesehatan, dan juga yang paling berbahaya ialah sampah yang berasal atau terbuat dari plastik, karena plastik tersebut akan lebbih sulit di hancurkan ataupun juga di musnahkan. Namun jika plastik di bakar akan menimbulkan asal yang beracun dan juga sangat berbaya bagi kesehatan yaitu jika didalam proses pembakarannya tidak sempurna maka palstik tersebut akan terjadi pengurai di udara yang mana dapat segai diloksin, dan senyawa ini juga sangat berbahaya apabila terhirup manusia, dan dampaknya akan memicu tejadinya kaker, hepatitis, pembengkakan hati, gaguan sistem saraf, dan jug memicu akan terjadinya depresi. Selain penyakit sampah plastik ini dapat menyebabkan banjir sehingga dapat menjadi banjir terparah dan juga dapat merusak turbin waduk, karena dari itu 
marilah kita sama sama menjaga kesehatan dan juga lingkungan dari banyaknya sampah kantong plastik yang digunakan oleh manusia. (Natsir, M. (2017))

sanksi merupakan sebuah peringatan untuk seseorang dalaam melakukan kesalahan maka akan diberi sanksi, entah itu sanksi berat dan juga ringan. Dalam sanksi pembuangan sampah sembarangan ini ada dua, yang pertama yaitu menurut Perda Nomor 3 tahun 2013 yang menjelaskan tentang pengelolaan sampah yang dapat ditegakkan oleh dinas lingkungan hidup DKI jakarta, dan kemudian apabila warga membuang sampah kesungai dan diketahui oleh petugas maka akan mendapatkan denda ( bayar denda) dengan senilai Rp. 300.000 dan bagi dalam penetapan perda yang membuang sampah sembarangan akan dikenai denda senilai Rp. 500.000. Tidak ada ketentuan denda minimal yang dapat diatur perda ini. Kedua, Perda No 8 Tahun 2007 yang menjelaskan tentang ketertiban umum yang ditegakkan satpol PP, di dalam Perd ini, orang - orang tidak melakukan pembuangan sampah secara tertib maka akan dikenakan sanksi tindak pidana ringan yaitu sebuah pidana penjara 10 hari sampai hingga 2 bulan atau juga dengan memakai denda yang senilai Rp. 100.000 sampai hingga rp. 20.000.000 . tetapi apabila yang membuang sampah itu masih anak-anak maka sanksi itu tidak di pakai, tetapi di gantti dengan cara menegur dan menyuruh anak itu agar membuang sampah ke tong sampah, dan apabila di sekitar tempat tinggal tidak ada tong sampah maka dengan cara membuat tong sampah dari kayu atau juga dari bahan bekas lainnya.( Suharwati, S. I., \& Rahman, A. M. (2018).

Adapun juga peraturan dari Perda di derah denpasar ini yang berisi tentang bahwa kebersihan dan keterttiban umum dan juga sebagimana yang telah diubah mellui Perda kota denpasar dengan no 3 tahaun 2000 mengenai tentang perubahan atas peraturan daerah denpasar dan juga ada No.15 ahun 1993 mengenai kebersihan dan ketertiban umum di kota denpasar, serrta menetapkan rambu-rambu sebgai dari suatu upaya agar dapat menanggulangi sampah, didasari adanya pembentukan perda ini relatif lama tetapi dalam mengenai permasalahan sampah ini belum juga dapat ditanggulangi secara tuntas bahkan semakin bermasalah tiada lain juga disebabkan oleh banyaknya tau pesatnya dari suatuu pertumbuhan penduduk, sehingga perkembangan di permukiman semakin meluas maka akan merupakan kendal dalm meupayakn mencari suatu tempat untuk menanggulangi permasalahan sampah ( penmpungan ). Terutama ialah adanya kesadaraan masyarakat yang masih sangat acuh serta membuang sampah dengan seenaknya saja. (Syaharuddin, S. (2020) 


\section{Simpulan}

Hukum dari area modern menetapkan tentang syarat serta pula norma-norma yang bermanfaat selaku pengatur dari terdapatnya aksi perbuatan manusia dengan mempunyai suatu tujuan melindungi area dari terdapatnya kehancuran serta sesuatu kemerosostaan mutunya supaya bisa menjamin kelestarian seta secara selalu bisa diggnakan oleh generasi saat ini serta seterusnya ataupun mendatang serta sebaik-baiknya hukum area klasik ialah hukum yang menetapkan.

Suatu kesatuan serta norma-norma yang bertujuan untuk menjamin pemakaian serta pula hukum modern ini iala suatu organisasi kepada sesuatu area yang sehingga watak serat sifat dari suatu araea sendiri bisa lebih banyak, suatu ekologi dengan area ini hinggaaraemodern ini, mempunyai watak yang utuh merata ataupun diucap komprehensif intergral yang mana senantiasa terletak dalam sesuatu sinamik dengan mempunyai suatu watak serta sifat yang luas. Pengelolaaan kawasan hidup di daerah tiap-tiap yang di atur dalam undang - undang no 23. tahun 1907 yang mana tentang pengelolaan area hidup pemahaman hukum yakni suatu pemahamanyang berasal dari dalam diri supaya bisa mematuh seluuruh peraturan peraturan yang sudah terbuat bersama pemahaman hukum jaga , yakni pemahaman tentang apa yang akan kita jalani ataupun kita pula berbuat paling utama perbuatan terhadap orang lain 


\section{Daftar Pustaka}

Ahya, RR, Syaharuddin, S., \& Rahman, AM (2020). Sikap Peduli Lingkungan Rumah Tangga Lanting Sebagai Sumber Belajar IPS. Jurnal Inovasi Ilmu Sosial , 2 (1), 66-74.

Bachtiar, E., Duwila, A. A., Chaerul, M., Affandy, N. A., Makbul, R., Tanjung, R., ... \& Simarmata, M. M. (2021). Pengetahuan Kebencanaan dan Lingkungan. Yayasan Kita Menulis.

Deasy, A. (2020). Studi Efektifitas Bank Sampah Sebagai Salah Satu Pendekatan dalam Pengelolaan Sampah Tingkat Sekolah Menengah Atas (SMA) di Banjarmasin. JPG (Jurnal Pendidikan Geografi), 3(5), 22-37.

Hadiyati, N., \& Cindo, C. (2021). KONTEKSTUALISASI PENCEMARAN EKOSISTEM LAUT DALAM MENCAPAI SDGS: SUATU KAJIAN HUKUM LINGKUNGAN DI INDONESIA. NUSANTARA: Jurnal Ilmu Pengetahuan Sosial, 8(3), 300-313.

Natsir, M. (2017). Analisis Permasalahan Banjir Wilayah Kelurahan Karunrung Kecamatan Rappocini Kota Makassar (Doctoral dissertation, UIN Alauddin Makassar).

Qodriyatun, S. N. (2021). Pembangkit Listrik Tenaga Sampah: Antara Permasalahan Lingkungan dan Percepatan Pembangunan Energi Terbarukan. Aspirasi: Jurnal Masalah-masalah Sosial, 12(1), 63-84.

Razikin, P., Kumalawati, R., \& Arisanty, D. (2017). Strategi Penangulangan Bencana Banjir Berdasarkan Persepsi Masyarakat Di Kecamatan Barabai Kabupaten Hulu Sungai Tengah. JPG (Jurnal Pendidikan Geografi), 4(1).

Suharwati, S. I., \& Rahman, A. M. (2018). Menumbuhkan Karakter Cinta Lingkungan dalam Pembelajaran IPS di Sekolah Dasar Melalui Outdoor Study.

Syaharuddin, S., Hidayanti, H., \& Mutiani, M. (2020). Peran Bank Sampah dalam Meningkatkan Kesadaran Lingkungan Masyarakat. Jurnal Inovasi Ilmu Sosial , 1 (2), 129-138.

Syahrin, MA, Syaharuddin, S., \& Rahman, AM (2020). Kepedulian Lingkungan Masyarakat Kampung Hijau, Sungai Bilu Banjarmasin. Jurnal Ilmu Sosial Kalimantan , 1 (2), 191-200 